\title{
Systematization and embryological and anatomical study of mirror-image dextrocardias, dextroversions, and laevoversions
}

\author{
María V. de la Cruz, Guillermo Anselmi, Luis Muños-Castellanos, \\ Bernardo Nadal-Ginard, and Simón Muñoz-Armas \\ From the Department of Embryology, National Institute of Cardiology of Mexico; \\ the Department of Paediatric Cardiology, Hospital Universitario, Caracas, Venezuela; \\ and the National Institute of Cardiology, Mexico
}

The study of the embryological development of the heart and the viscera permits the establishment of an interrelation between the visceral situs, the malpositions of the heart, the truncoconal morphologies, and the position of the cardiac chambers; this in turn enables a correct classification and a precise nomenclature.

Situs solitus, which is characterized by an anatomical right atrium, the greater lobe of the liver, and the suprahepatic segment of the inferior vena cava being placed on the right, is divided according to the direction of the apex into: (a) normally placed heart, with apex to the left, and (b) dextroversion, with apex to the right. Each one of these positions of the heart may in turn present with or without ventricular inversion.

Situs inversus, characterized by an anatomical right atrium, greater lobe of the liver, and the suprahepatic portion of the inferior vena cava being placed to the left, is divided according to the position of the apex into: (a) mirror-image dextrocardia, with a right-sided apex and (b) laevoversion, with a left-sided apex. Each one of these positions of the heart may also have or not have ventricular inversion.

The different malpositions of the heart in situs solitus or in situs inversus, with or without ventricular inversion with a right-sided apex or a left-sided apex, are divided into three subgroups according to the truncoconal morphology: without transposition of the great vessels, with transposition of the great vessels, and with common trunk.

The diagnosis must be done carefully, establishing in the first place the visceroatrial situs and its relation to the direction of the apex in order to diagnose the type of malposition of the heart. If there are two vessels, their mutual relation is established, which permits the diagnosis of the type of truncoconal morphology; through it the spatial position of the ventricles may be established by inference and, consequently, the atrioventricular relation.

This paper describes the malformations associated with malpositioning of the heart, and anatomical examples of each type of malposition are presented.

Malpositioning of the heart has usually been studied assuming that it is an isolated organ and ignoring the fact that it is integrated in the visceral context of a specific situs (Lev and Rowlatt, I96I). Furthermore, the position of the cardiac cavities has not been related to the situs of which it is a part, and this has led to erroneous concepts such as 'atrial inversion' (Lev and Rowlatt, 196I; Van Praagh et al., 1964; Calderón Montero et al., 1965; Campbell and Deuchar, 1966; Stanger et al., 1968). This Received 21 December 1970. confusion has become evident in the great number of classifications which have appeared in the published material, some using a clinical criterion and others an anatomical criterion but all lacking in solid embryological bases (Hanson and Tabakin, I96I; Calderón Montero et al., 1965; Jue et al., 1966). These erroneous classifications are full of nomenclatures many of which are incorrect (Berri, 1958).

On the basis of the study of the embryological development of the heart and the 
viscera, we can establish an interrelation between the visceral situs, the malpositioning of the heart, the truncoconal morphologies, and the position of the cardiac chambers, which will lead to the establishment of a correct classification and a precise nomenclature. We believe that the clinician who takes into consideration these interrelations can better integrate his diagnoses.

We shall not study heterotaxias, since this is a problem, the morphogenesis of which we do not yet fully understand. Nor shall we include displacements of the heart due to extracardiac causes (dextro or laevopositions of the heart), since these do not constitute a disturbance in the development of the heart and of the visceral situs.

Embryological and anatomical bases of malpositions of heart and rules for diagnosis

The diagnosis of malpositions of the heart and associated malformations should be made using a logical, orderly sequence, determining in the first place the visceroatrial situs and its relation to the direction of the apex in order to diagnose the type of malposition of the heart. In the second place, the truncoconal morphology must be studied, establishing whether there are one or two vessels arising from the heart. Where there are two vessels, they should be analysed in order to determine their mutual relations. This permits the diagnosis of the type of truncoconal morphology, and once this is determined, one can infer the spatial position of the ventricles and consequently the atrioventricular relation.

Visceral situs The system of symmetry is established quite early during the development of the embryo. The normal blastoderm is characterized because the right half exhibits right developmental potentialities and the left half exhibits left developmental potentialities. Later on they manifest themselves as the anatomical image of the visceral situs solitus which is the normal spatial position of the viscera within the bilateral system of symmetry in which the right anatomical structures are placed on the right and the left anatomical structures are placed on the left. It may happen that in very early stages of development, the right half of the blastoderm develops potentialities which normally characterize the left half, while the left half develops potentialities which normally characterize the right half. This embryological disturbance is expressed anatomically by the visceral situs inversus which is the spatial position of the viscera in which the right anatomical struc- tures are placed on the left and the left anatomical structures are placed on the right, constituting the mirror-image of situs solitus (de la Cruz et al., 1967).

In both forms of situs there may be disturbances in the positions of the viscera in relation to the situs. In these cases, those that invariably maintain the normal anatomical position characteristic of the situs are the atria, the position of the liver segments, and the suprahepatic portion of the inferior vena cava. There is a constant hepato-cavo-atrial concordance in each situs (de la Cruz et al. 1967; Espino-Vela et al., 1970).

Direction of apex In situs solitus, during the 8th week of gestation, the cardiac apex is directed to the right and during the 9th week it is progressively displaced until it reaches its normal left-sided position for this situs (Licata, 1954). If the heart in a situs solitus remains with a right-sided apex, it will constitute a malposition of the heart designated as dextroversion.

In situs inversus, the apex of the heart must be found initially directed to the left, and later it is displaced to the right, following a mirror-image course with respect to that of the normal heart of situs solitus, thereby reaching its final position: right-sided apex, i.e. situs inversus with right-sided apex, which is designated as mirror-image dextrocardia. If the heart remains in the first position, that is, a left-sided apex, it is designated as laevoversion.

Table I shows a summary of the fundamental elements which characterize both situs and the position of the heart in relation to the visceral situs.

Position of atria Each of the atria originates from one of the cardiac primordia; therefore they are not of mixed origin (de la Cruz et al., 1967). In situs solitus, the atrium placed

TABLE I

I: $\begin{aligned} & \text { Situs solitus } \\ & \text { (venous atrium, greater } \\ & \text { hepatic lobe, and supra- } \\ & \text { hepatic segment of the } \\ & \text { inferior vena cava, on } \\ & \text { the right side) }\end{aligned}$
II: $\begin{aligned} & \text { Situs inversus } \\ & \text { (venous atrium, greater } \\ & \text { hepatic lobe, and supra- with right-sided apex = dextroversion } \\ & \begin{array}{l}\text { hepatic segment of the } \\ \text { inferior vena cava on } \\ \text { the left side) }\end{array}\end{aligned}\left\{\begin{array}{l}\text { A: with right-sided apex = mirror-image dextro } \\ \text { cardia } \\ \text { B: with left-sided apex }=\text { laevoversion }\end{array}\right.$


on the right originates from the right cardiac primordium and consequently it has the anatomical features of the right atrium. The atrium placed on the left originates from the left cardiac primordium and consequently it has the features of the anatomical left atrium, whatever the position of the ventricles and the apex.

In situs inversus, the atrium placed on the right originates from the right cardiac primordium which has developmental potentialities of left development, the same as the entire right half of the blastoderm (de la Cruz et al., 1967). Therefore, it has the features of the anatomically left atrium. The atrium placed on the left will therefore be the anatomically right atrium. This concordant position of the atria with the situs is maintained constant whatever the position of the ventricles and the direction of the apex (Espino-Vela et al., 1970).

The position of the anatomically right atrium to the left in situs inversus is the normal visceroatrial relation in this situs and therefore 'atrial inversion' (Lev and Rowlatt, 196I) does not exist.
Position of ventricles The bulbus aorticus (later the truncus) which will give rise to the ascending portion of the aortic arch and the trunk of the pulmonary artery; the bulbus cordis, which will give rise to the anatomically right ventricle and the infundibulum of the anatomically left ventricle; and the primitive ventricle which will give rise to the anatomically left ventricle all originate from the fusion of the two cardiac primordia: a right one with right-sided developmental potentialities and a left one with left-sided developmental potentialities. On the contrary, the anatomically right atrium originates from the right primordium and the anatomically left atrium from the left primordium (de la Cruz et al., 1967). The normal bulboventricular loop of situs solitus is convex to the right and concave to the left, which determines that the anatomically right ventricle (bulbus cordis) remains on the right and the anatomically left ventricle (primitive ventricle) is placed on the left (Davis, 1927; Streeter, 1948), and each of these ventricles is related to its respective atrium. Dextroversion (abnormally placed heart in situs solitus) without ventricular

FIG. I Dextroversion without ventricular inversion and without transposition of the great vessels. $(A)$ External view of the heart with the apex directed to the right. Note that the greater lobe of the liver is on the right side. The pulmonary artery $(P)$ crosses in front of the aorta $(\mathrm{Ao})$ and it is directed from right to left and from the front backwards.

$(B)$ Internal view of the cardiac chambers placed on the right. Atrioventricular relation. Anatomically right atrium $(R A)$ placed on the right, receiving the inferior vena cava (IVC) and communicating with the anatomically right ventricle $(R V)$ also placed on the right side. $(C)$ Relation of the great vessels to the ventricles. Pulmonary artery $(P)$ arising in front of the crista supraventricularis of the anatomically right ventricle $(R V)$ placed on the right side.
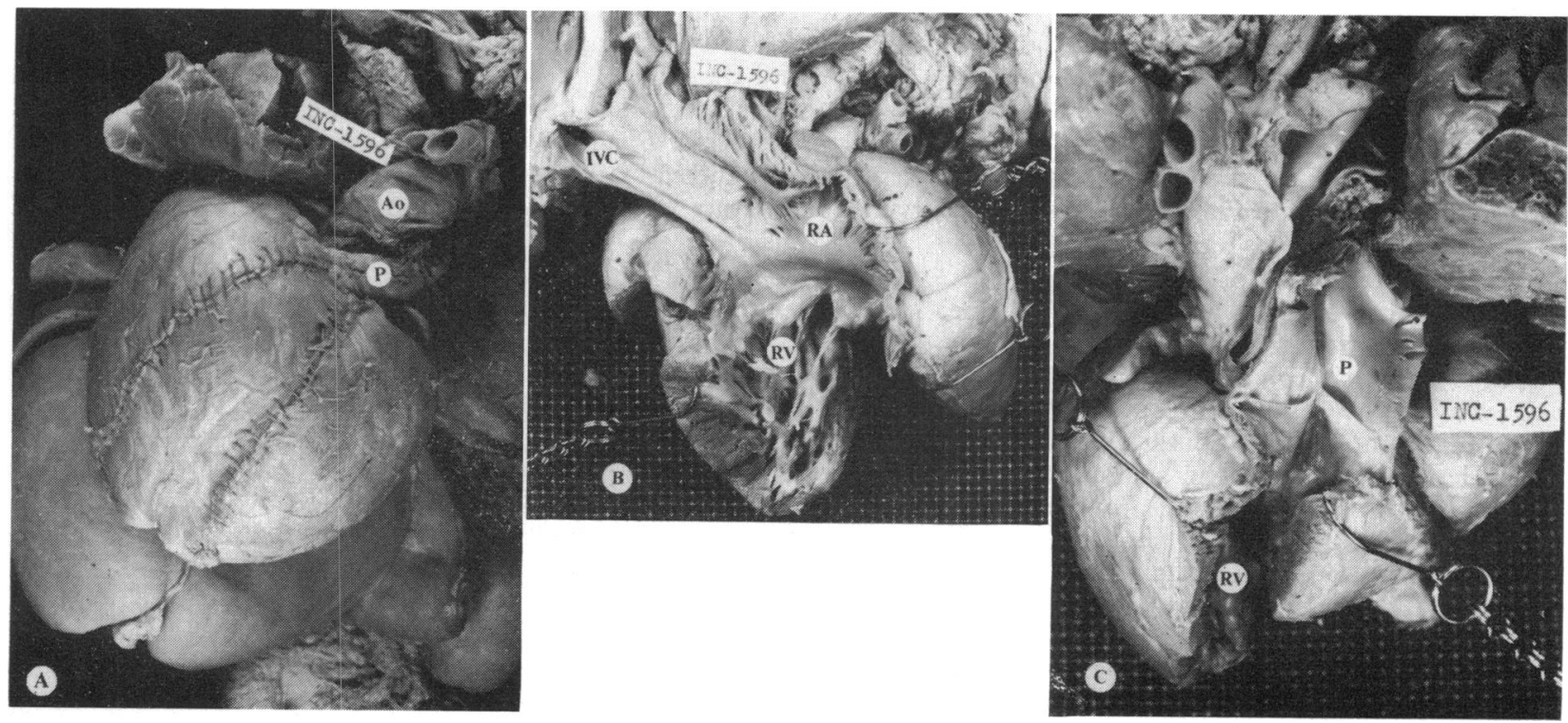

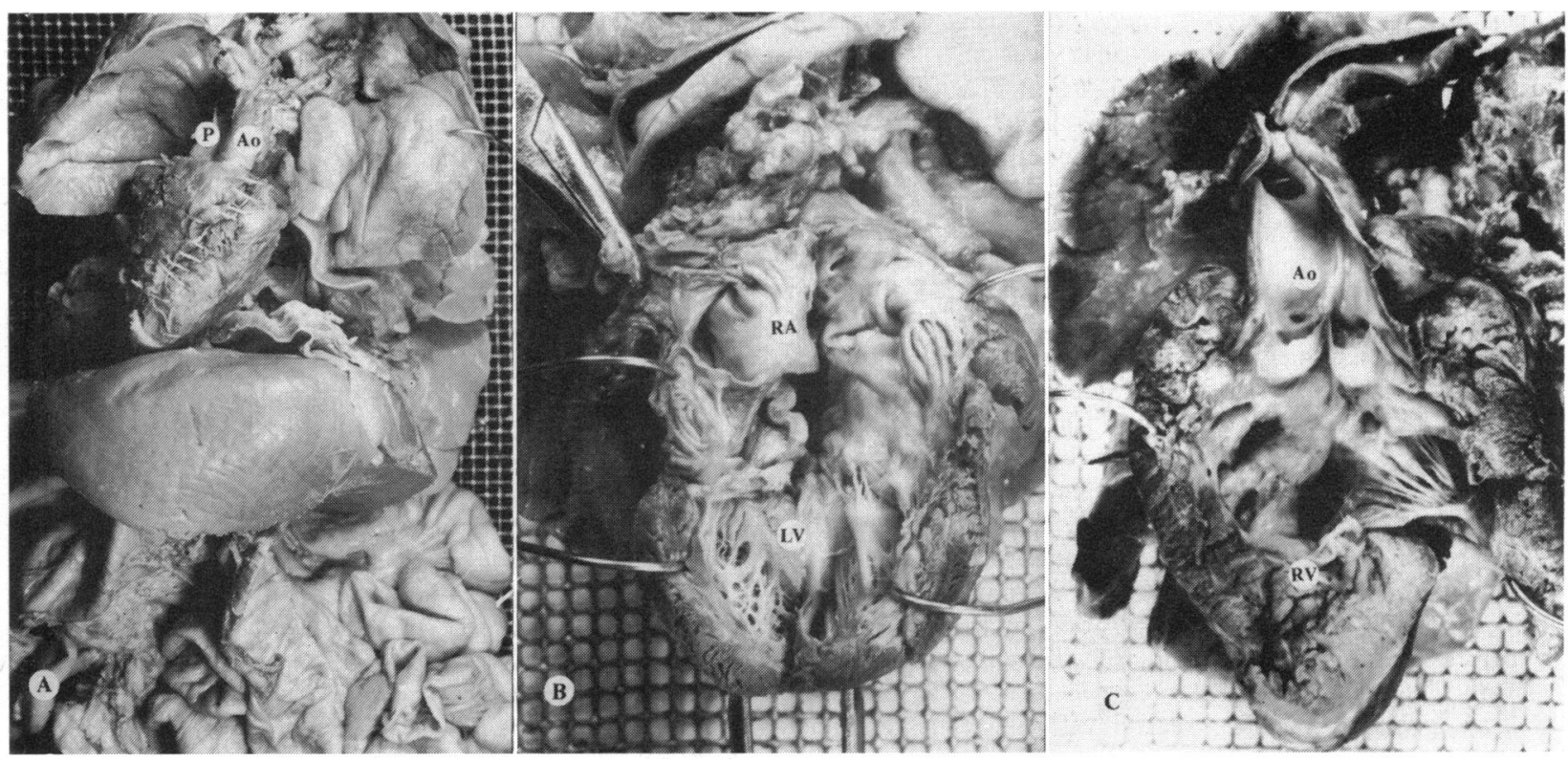

FIG. 2 Dextroversion with ventricular inversion and with transposition of the great vessels.

(A) External view of the heart with its apex directed to the right. Observe the greater lobe of the liver placed on the right side. The aorta $(A o)$ is anterior, parallel, and placed to the left of the pulmonary artery $(P)$. (B) Internal view of the cardiac chambers placed to the right side.

Atrioventricular relation. Anatomically right atrium $(R A)$ placed on the right and communicating with the anatomically left ventricle $(L V)$ also placed on the right. $(C)$ Relation of the great vessels with the ventricles. The aorta $(A o)$ arises in front of the crista supraventricularis of the anatomically right ventricle $(R V)$ placed on the left side.

inversion is characterized because the atria will remain concordant with the situs: the anatomically right atrium to the right and the anatomically left atrium to the left. The ventricles will also be related with their situs: the anatomically right ventricle placed on the right and the anatomically left ventricle placed to the left, communicating with their respective atria (Fig. IA and B).

In dextroversion it may happen that the potentialities of both primordia are inverted at the level of the bulboventricular loop and of the truncus and not of the atria. For this reason the chambers of mixed origin will be affected and will give rise to an abnormal bulboventricular loop, convex to the left and concave to the right. This causes the anatomically right ventricle (bulbus cordis) to be placed on the left and the anatomically left ventricle (primitive ventricle) to remain on the right side, an abnormal ventricular position for a situs solitus. On the other hand, the atria have not been affected by this process and they will therefore remain in the normal situation which corresponds to situs solitus (anatomically right atrium to the right and anatomically left atrium to the left) and in agreement with the situs; however, they communicate with ventricles which are not the normal ones for the situs: we designate this anatomical relation a ventricular inversion in situs solitus with dextroversion (de la Cruz et al., 1967) (compare Fig. 2A and B with Fig. IA and B).

In situs inversus due to inversion of the developmental potentialities of the right and left halves of the embryo, the primordia from which the heart originates will also be inverted; therefore the right primordium has the developmental potentialities of the left one and vice versa, giving rise to a heart in which the anatomically right atrium is placed on the left side and vice versa, the normal situation for the atria of this situs. The bulboventricular loop is convex to the left and concave to the right, which is a normal loop for this situs, and this causes the anatomically right ventricle (bulbus cordis) to be placed on the left and the anatomically left ventricle (primitive ventricle) to be placed on the right, each ventricle in agreement with its respective atrium. This is none other than the anatomical picture of a normal heart in situs inversus. If the apex of the heart is 

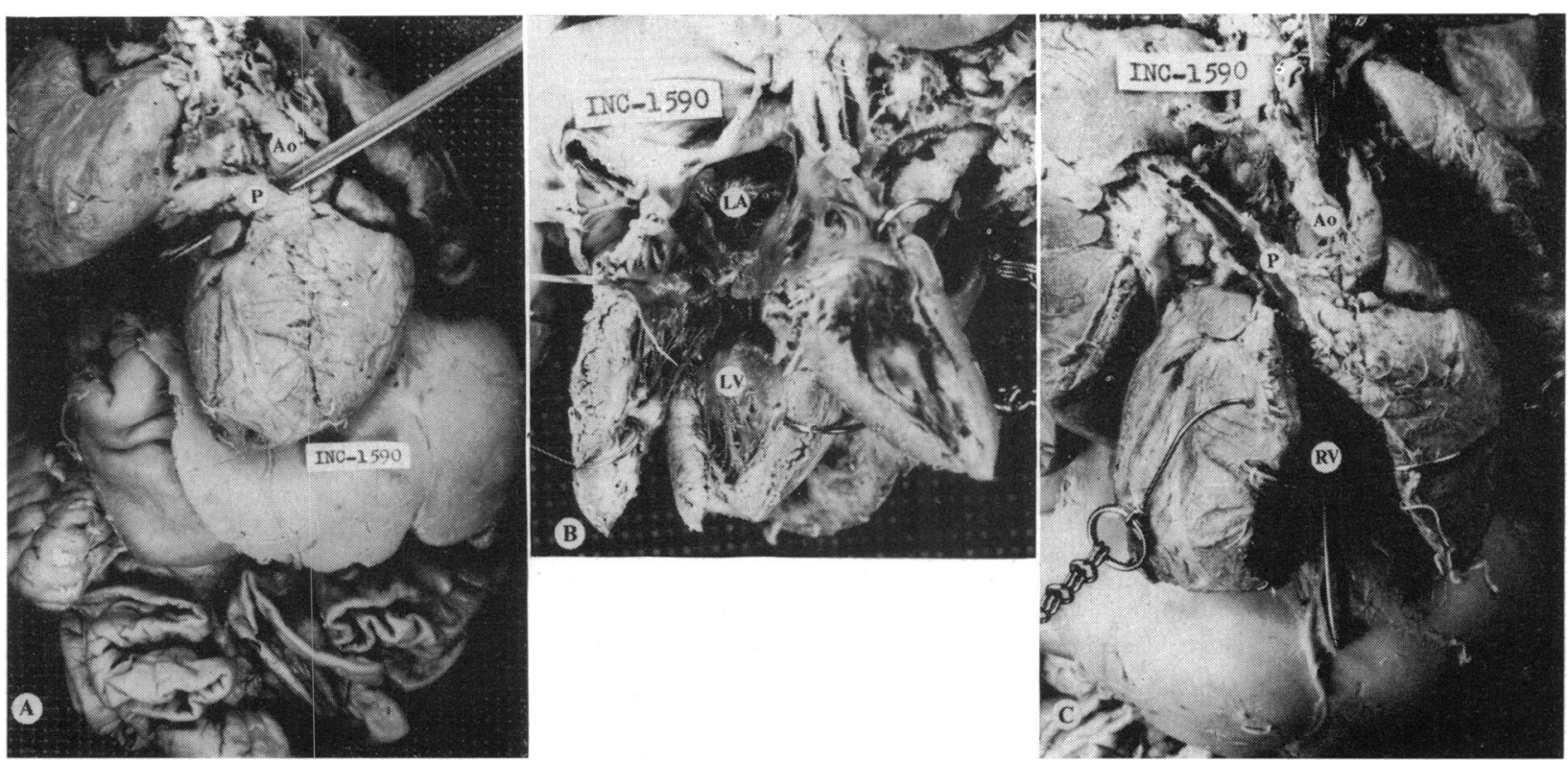

FIG. 3 Mirror-image dextrocardia without ventricular inversion and without transposition of the great vessels. $(A)$ External view of the heart. Notice the apex of the heart directed to the right, the greater lobe of the liver on the right side and the pulmonary artery $(P)$ directed from left to right and from the front backward crossing in front of the aorta $(A o)$. (B) Internal view of the cardiac chambers placed on the right. Atrioventricular relation. Anatomically left atrium $(L A)$ placed on the right communicating with the anatomically left ventricle $(L V)$ also placed on the right. $(C)$ Relation of the great vessels with the ventricles. Pulmonary artery $(P)$ arising from the anatomically right ventricle $(R V)$ placed on the left side.

directed to the right it is called mirror-image dextrocardia (Fig. 3A and B). If it is directed to the left, laevoversion.

In situs inversus it may happen that the developmental potentialities of both cardiac primordia are inverted at the level of the bulboventricular loop and the truncus (but not of the atria); therefore, the only affected cavities are those of a mixed origin, thus giving rise to an abnormal bulboventricular loop for this situs: convex to the right and concave to the left and this causes the anatomically right ventricle (bulbus cordis) to be placed on the right and the anatomically left ventricle (primitive ventricle) to be placed on the left, an abnormal ventricular position for situs inversus, since the ventricles do not agree with their respective atria; the latter maintain their normal position for situs inversus: anatomically right atrium placed on the left and vice versa, which is the normal atrial position for this situs (de la Cruz et al., 1967) (compare Fig. 4A and B with Fig. 3A and $B)$. Therefore, there is no atrial inversion.

This picture may be seen in a heart the apex of which is directed to the right, and it is called ventricular inversion in situs inversus with mirror-image dextrocardia, or in a heart with its apex directed to the left and it is then designated ventricular inversion in situs inversus with laevoversion.

Table 2 shows a summary of the fundamental elements which characterize both situs, the position of the heart in relation to the visceral situs and the position of the ventricles in relation to the situs and the position of the heart.

Truncoconal morphologies The three fundamental truncoconal morphologies seen in situs solitus and in situs inversus with and without ventricular inversion are (a) without transposition of the great vessels, (b) with transposition of the great vessels, and (c) with common truncus (de la Cruz et al., 1967; Espino-Vela et al., 1970).

Truncoconal morphologies in situs solitus without ventricular inversion

Without transposition of the great vessels (Fig. I) The truncus-conus is formed by two portions: the truncus which gives rise to the ascending portion of the aortic arch and to the 
I: Situs solitus

II: Situs inversus

B: Situs inversus + left-sided apex $=$ laevoversion

(venous atrium, greater hepatic lobe, and suprahepatic segment of inferior vena cava to left) (a) without ventricular inversion (anatomically right ventricle on right)

(venous atrium, greater lobe of liver, and suprahepatic segment of inferior vena cava on right)

B: Situs solitus + right-sided apex $=$ dextroversion (venous atrium, greater lobe of liver, and suprahepatic segment of inferior vena cava on right)

(b) with ventricular inversion (anatomically right ventricle on left)

(a) without ventricular inversion (anatomically right ventricle on right) (Fig. I)

(b) with ventricular inversion (anatomically right ventricle on left) (Fig. 2) (a) without ventricular inversion (anatomically right ventricle on left) (Fig. 3)

(b) with ventricular inversion (anatomically right ventricle on right) (Fig. 4)

(a) without ventricular inversion (anatomically right ventricle on left)

(b) with ventricular inversion (anatomically right ventricle on right)

FIG. 4 Mirror-image dextrocardia with ventricular inversion without transposition of the great vessels. (A) External view of the heart. Notice the apex directed to the right and the greater lobe of the liver also placed on the right. The pulmonary artery $(P A)$ is directed from left to right and it crosses in front of the aorta $(A o)$. (B) Internal view of the cardiac chambers placed on the left. Atrioventricular relation. Anatomically right atrium $(R A)$ placed on the left and communicating with the anatomically left ventricle $(L V)$ placed on the left. $(C)$ Relation of the great vessels with the ventricles. Internal view of the anatomically right ventricle $(R V)$ placed on the right, from which the pulmonary artery arises $(P A)$ in front of the crista supraventricularis (CS-V); the aorta $(A o)$ is placed behind the crista and it overrides the interventricular septum.
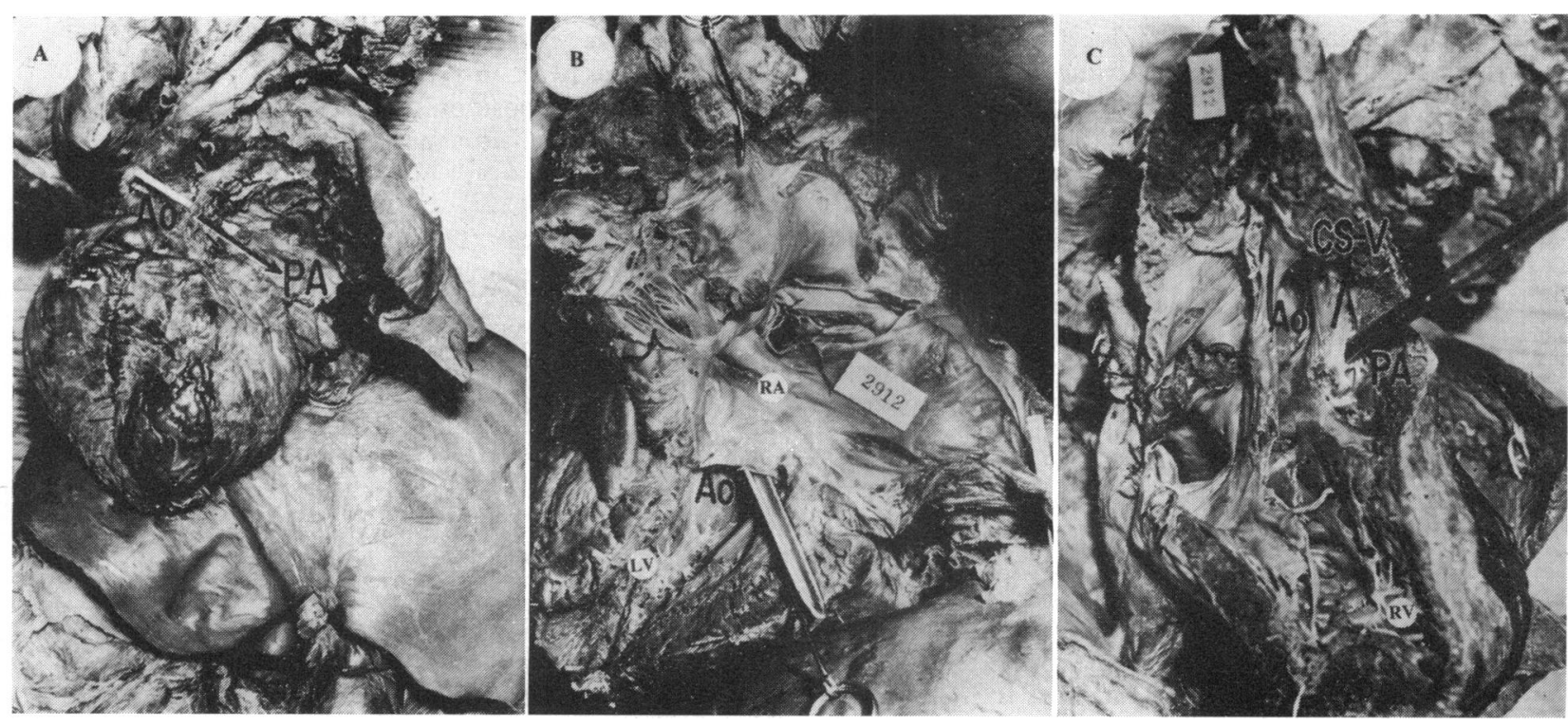
trunk of the pulmonary artery, and the conus which gives rise to the infundibula of both ventricles. The septation of the truncus-conus is a consequence of, or the result of, the fusion of the two truncoconal ridges which normally arise with a clockwise rotation of $180^{\circ}$ (Kramer, 1942). Because of this rotation, the infundibulum of the anatomically right ventricle, which is always anterior, communicates with the branches of the pulmonary artery, which are posterior; the infundibulum of the anatomically left ventricle, which is always posterior, communicates with the horizontal portion of the aortic arch, which is anterior. This process causes the great vessels to cross each other normally; the pulmonary artery being anterior, is directed from right to left and from the front backwards. The aorta is posterior and it is directed to the right, and from the back forward. The anteriorly placed pulmonary artery directed from right to left indicates that the anatomically right ventricle is placed on the right (Fig. IA and $\mathrm{C}$ ).

With transposition of the great vessels (Fig. 5) The straight development of the truncoconal ridges is the reason why the posteriorly placed branches of the pulmonary artery communicate with the infundibulum of the anatomically left ventricle, which is posterior. It is also responsible for the fact that the horizontal portion of the aortic arch, which is anterior, communicates with the infundibulum of the anatomically right ventricle, which is anterior (de la Cruz and da Rocha, 1956). Consequently the aorta is anterior, right-sided, and parallel to the pulmonary artery. The transposed aorta, placed to the right, indicates that the anatomically right ventricle is placed on the right (Fig. 5A and $\mathrm{C}$ ).

With common truncus When the truncoconal septum does not develop, there is a single vessel emerging from the heart (de la Cruz and da Rocha, 1956), which is directed from the right to the left and from the front backward; this defect is designated as persistent common trunk. When the common trunk is directed from right to left and from the front backward, it means that the anatomically right ventricle is placed on the right (de la Cruz et al., 1967).

FIG. 5 Dextroversion without ventricular inversion with transposition of the great vessels.

(A) External view of the heart. Notice the apex directed to the right and the greater lobe of the liver also placed on the right side. The aorta $(A o)$ is parallel, anterior, and placed on the right side of the pulmonary artery $(P) .(B)$ Internal view of the cardiac chambers placed on the right side. Atrioventricular relation. Anatomically right atrium placed on the right $(R A)$ and communicating with the anatomically right ventricle $(R V)$, also placed on the right side. $(C)$ Relation of the great vessels to the ventricles. The aorta $(A o)$ arises in front of the crista supraventricularis, from the anatomically right ventricle $(R V)$ placed on the right side.
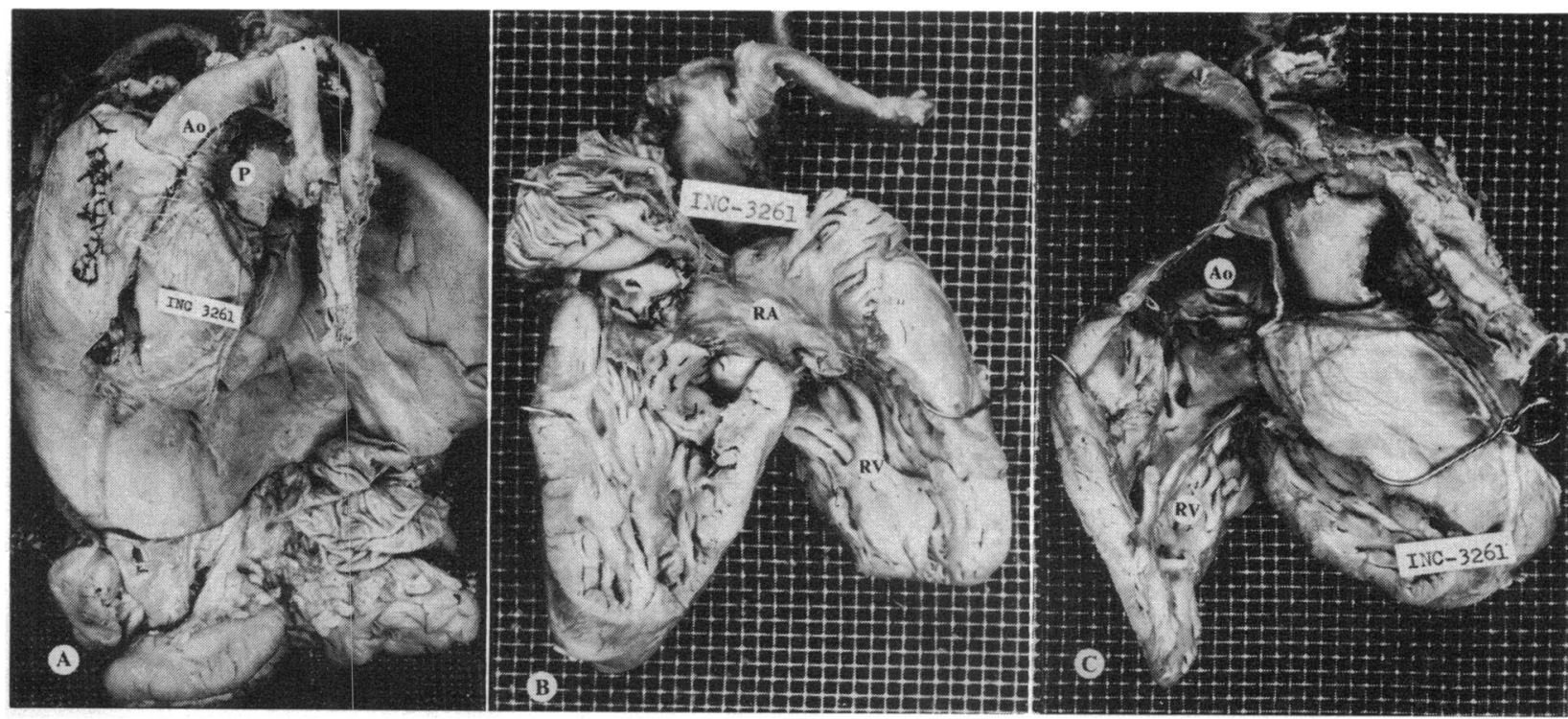

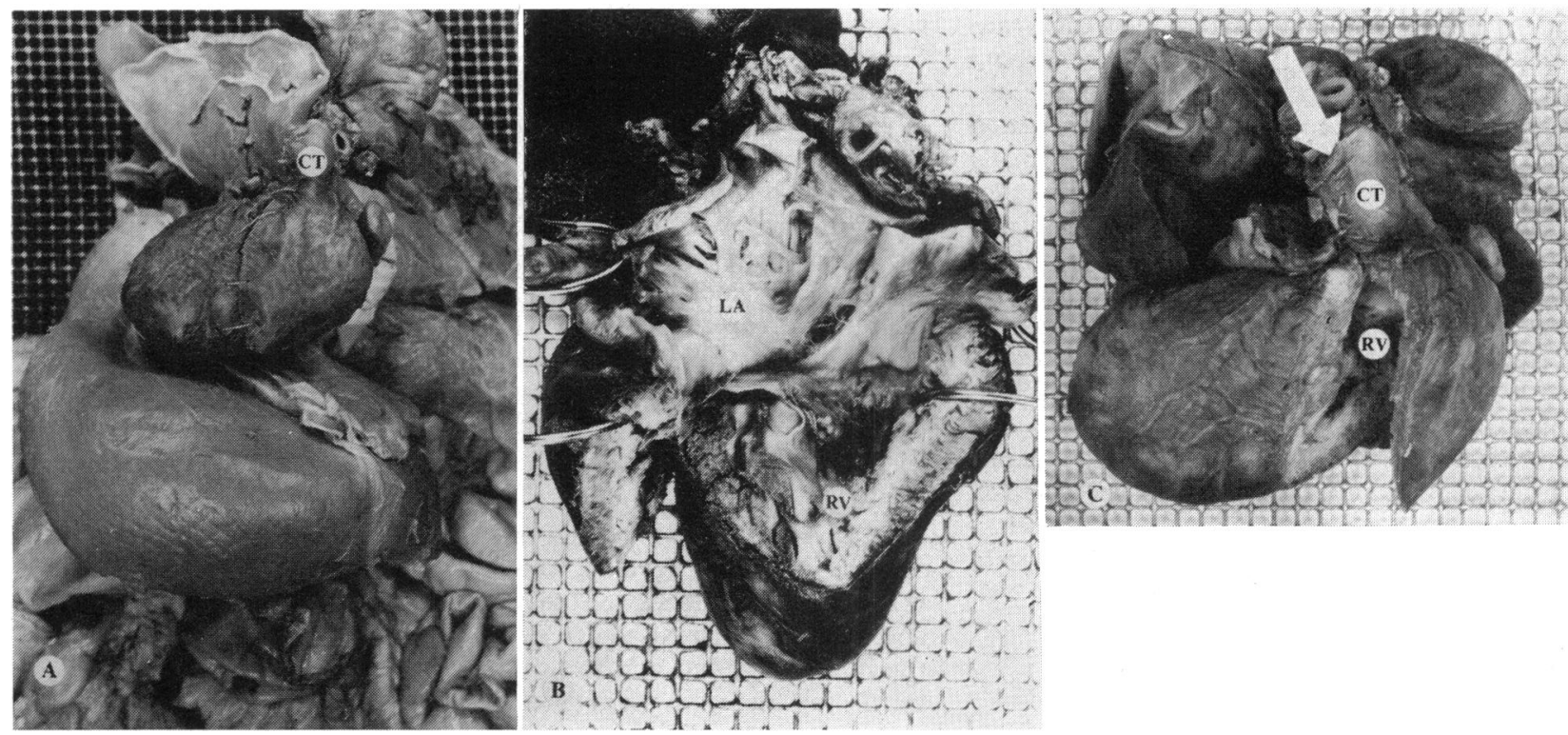

FI G. 6 Dextroversion with ventricular inversion with common trunk. $(A)$ External view of the heart with the apex directed to the right. The greater lobe of the liver is placed on the right side. The common trunk $(C T)$ is directed to the right and from the front backward.

(B) Internal view of the cardiac chambers placed to the left. Atrioventricular relation. The anatomically left atrium $(L A)$ is placed on the left side and it communicates with the anatomically right ventricle $(R V)$ placed on the left. $(C)$ Common trunk $(C T)$ arising from the anatomically right ventricle $(R V)$ placed on the left.

FIG. 7 Mirror-image dextrocardia without ventricular inversion with transposition of the great vessels. $(A)$ External view of the heart with its apex directed to the right. The greater lobe of the liver is on the left side. The aorta $(A o)$ is anterior, parallel, and placed to the left of the pulmonary artery $(P) .(B)$ Internal view of the cardiac chambers placed on the left side. Atrioventricular relation. Anatomically right atrium $(R A)$ placed on the left and communicating with the anatomically right ventricle $(R V)$ also placed on the left side. $(C)$ Relation of the great vessels to the ventricles. The aorta $(A o)$ arises in front of the crista supraventricularis from the anatomically right ventricle $(R V)$ placed on the left side.
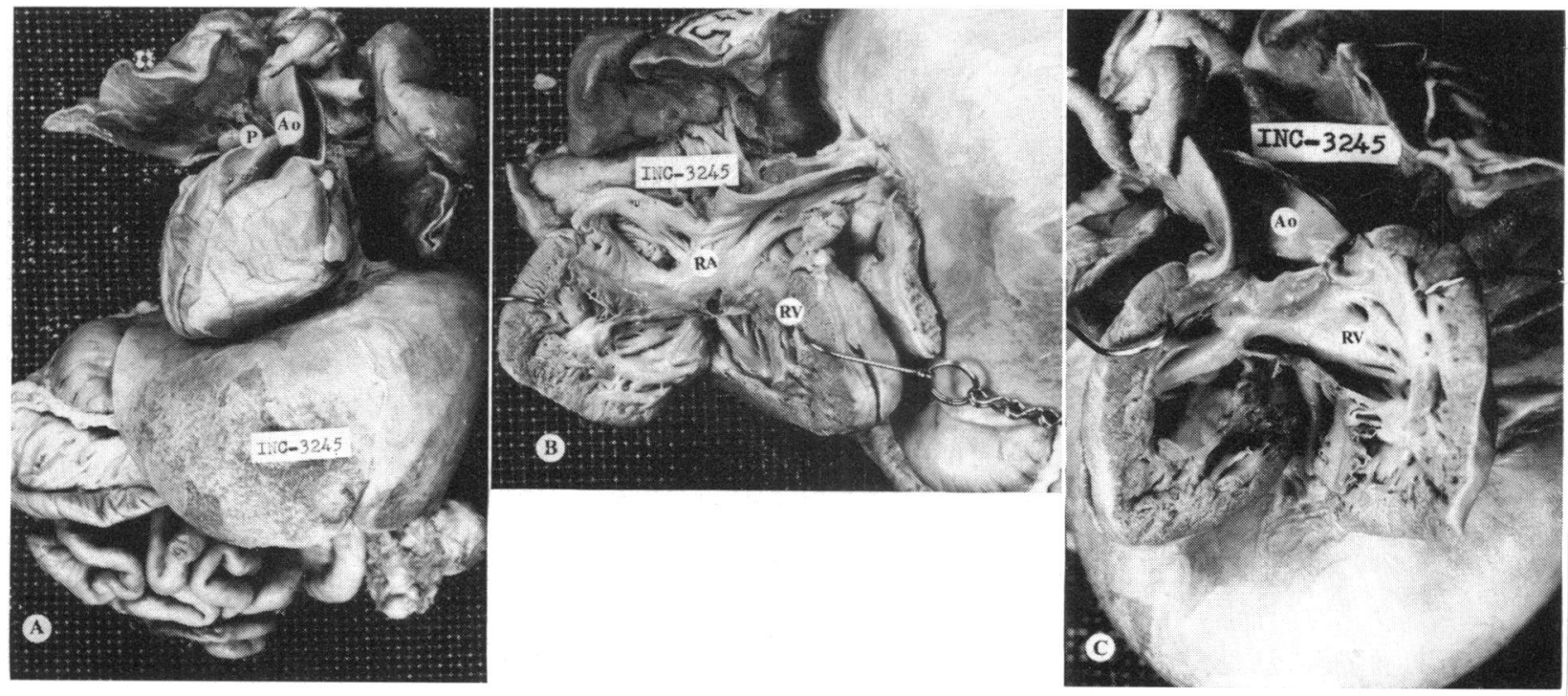

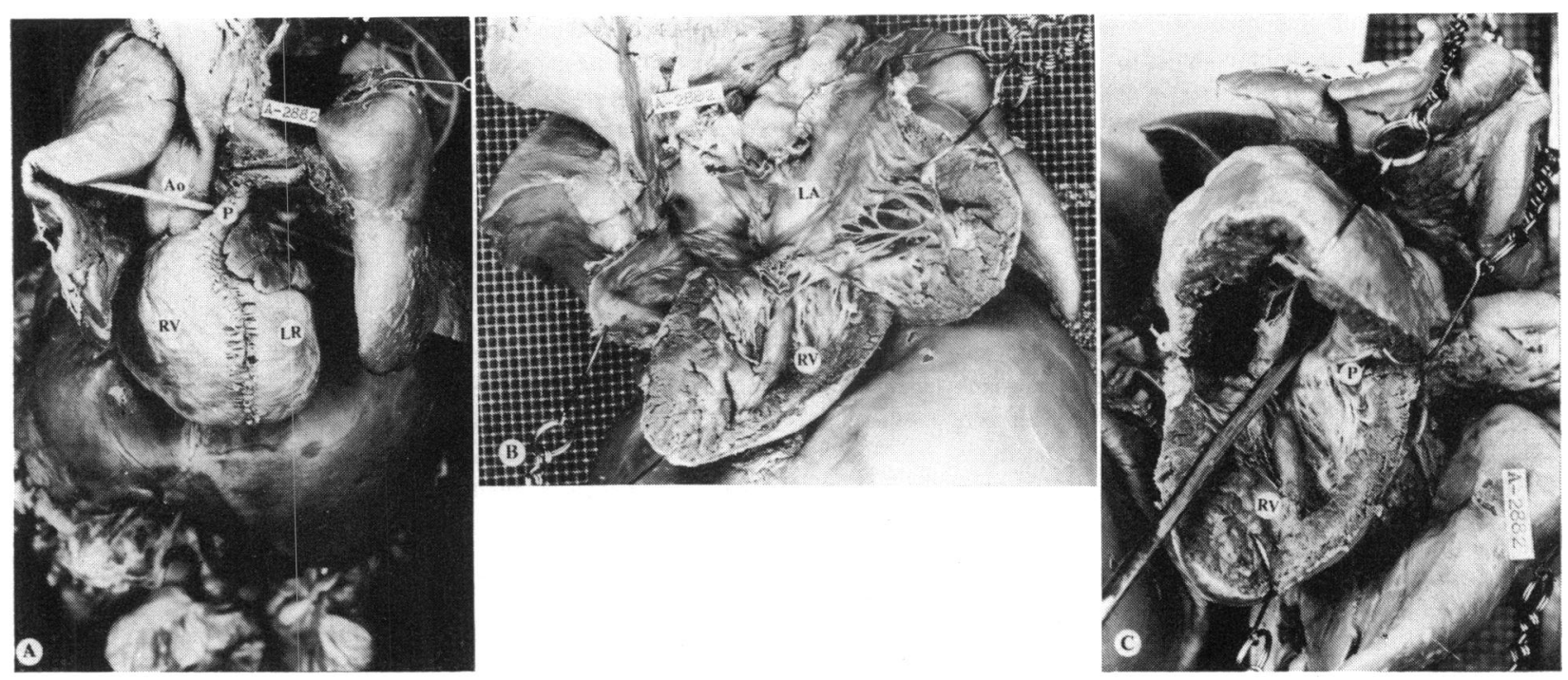

FIG. 8 Laevoversion with ventricular inversion without transposition of the great vessels.

(A) External view of the heart with the cardiac apex directed to the left. The greater lobe of the liver is on the left side. The pulmonary artery $(P)$ crosses in front of the aorta $(A o)$ and it is directed from right to left. $(B)$ Internal view of the cardiac cavities placed on the right side. Atrioventricular relation. The anatomically left atrium $(L A)$ is placed on the right and it communicates with the anatomically right ventricle $(R V)$ placed also on the right side.

$(C)$ Relation of the great vessels to the ventricles. The pulmonary artery $(P)$ arises in front of the crista supraventricularis of the anatomically right ventricle $(R V)$. The aorta (pointed by the stylet) arises behind this crista and overrides the interventricular septum.

Truncoconal morphologies in situs solitus with ventricular inversion

These are the mirror-images of the three truncoconal morphologies of the heart in situs solitus without ventricular inversion. They are called inversions of the vascular pedicle and they are always seen in association with ventricular inversions. This is due to the fact that the right half of the truncus-conus has left-sided potentialities and vice versa; it is also true of the bulbus cordis and the primitive ventricle, which is the determinant factor of ventricular inversion.

Without transposition of the great vessels The truncoconal septum has an anticlockwise rotation of 180 degrees, due to the inversion of the bulboventricular loop and the truncus; therefore the pulmonary artery is anterior and is directed from left to right and from the front backwards; the aorta is posterior and it is directed from right to left and from the back forwards. The anterior pulmonary artery directed from left to right is indicative of the fact that the anatomically right ventricle is placed on the left.
With transposition of the great vessels (Fig. 2) The truncoconal septum arises as a straight structure, but with a left-to-right orientation which is due to the inversion of the bulboventricular loop and the truncus. These two factors are responsible for the anterior origin of the aorta with respect to the pulmonary artery; however, the aorta is placed to the left of the pulmonary artery. The transposed and left-sided aorta indicates that the anatomically right ventricle is placed on the left (Fig. 2A and $\mathrm{C}$ ).

With common trunk (Fig. 6) When the truncoconal septum does not develop, a single vessel emerges from the heart. It is directed from left to right and from the front backwards. The left to right orientation of the common trunk indicates that the anatomically right ventricle is placed on the left (Fig. 6A and C).

Truncoconal morphologies in situs inversus without ventricular inversion

The truncoconal morphologies seen in situs inversus without ventricular inversion are the 
mirror-image of the three truncoconal morphologies of situs solitus without ventricular inversion due to the fact that the right half of the bulbus cordis, the primitive ventricle, and the truncus have the features of the normal left half of the heart in situs solitus and vice versa.

Without transposition of the great iessels (Fig. 3) The vascular pedicle of the heart in situs inversus without ventricular inversion. In these cases the pulmonary artery crosses the aorta from the front backward and from left to right, due to the fact that the truncoconal septum has an anticlockwise rotation of 180 degrees. The pulmonary artery is anterior and it is directed from the left to the right, indicating that the anatomically right ventricle is placed on the left side (Fig. 3A and C).

With transposition of the great vessels (Fig. 7) The aorta is anterior and placed to the left with respect to the pulmonary artery. This is due to the fact that the truncoconal septum besides being straight is oriented from left to right. The transposed aorta, placed to the left of the pulmonary artery, indicates that the anatomically right ventricle is placed on the left side (Fig. $7 \mathrm{~A}$ and $\mathrm{C}$ ).

With common truncus The single vessel emerges from the left and it is directed to the right and also from the front backward. The direction from left to right of the common trunk indicates that the anatomically right ventricle is placed on the left side.

Truncoconal morphologies in situs inversus with ventricular inversion

The features of the three truncoconal morphologies in situs inversus with ventricular inversion are due to the fact that the right half of the truncus, bulbus cordis, and primitive ventricle have features pertaining to the right and vice versa, which is abnormal for a heart in situs inversus.

Without transposition of the great vessels (Fig. 8) In these, the pulmonary artery crosses the aorta from the front backward and from right to left. This morphology is due to the fact that the truncoconal septum has a clockwise rotation of 180 degrees. The pulmonary artery which is anterior and directed from right to left indicates that the anatomically right ventricle is placed on the right side (Fig. 8A and $\mathrm{C}$ ).

With transposition of the great vessels (Fig. 9 and 10) The aorta is anterior and it is placed on the right side with respect to the pulmon- ary artery. This is because the truncoconal septum is straight and is directed from right to left. The transposed aorta placed on the right side of the pulmonary artery indicates the rightsided position of the anatomically right ventricle (Fig. 9A, C and IoA, C).

With common trunk The single vessel emerges from the heart from right to left and from the front backward. The left-to-right direction of the common trunk indicates the right-sided position of the anatomically right ventricle.

Unequal partitions and lateral positions in situs solitus and in situs inversus with and without ventricular inversion

The three truncoconal morphologies which are seen in situs solitus and in situs inversus with and without ventricular inversion may be associated with a lateral position. When there are two vessels, whether they are transposed or not, they may exhibit isolated lateral position as has been shown, or they may exhibit an unequal partition at the expense of the pulmonary artery or at the expense of the aorta exclusively, or unequal partition at the expense of the pulmonary artery or of the aorta and, in addition to this, a lateral position (de la Cruz and da Rocha, 1956).

Unequal partitions, lateral positions, or the association of both conditions do not change the rules established for the localization of the ventricles by means of the relations of the great vessels between them or of the direction of the common trunk in a given visceroatrial situs with or without ventricular inversion.

Unequal partition at the expense of the pulmonary artery or of the aorta is due to the fact that the truncoconal septum, either straight or rotated, develops within the territory belonging to one of the great vessels (de la Cruz and da Rocha, 1956). The unequal partition may extend throughout the entire length of the truncoconus or it may affect only a portion of it. In the first case it is expressed as a hypoplasia of the trunk with stenosis of the infundibulum of the affected vessels, and in the second place by isolated infundibular stenosis or hypoplasia of this vessel. Unequal partition may be of different degrees, either moderate or extreme, the latter giving rise anatomically to atresia of the corresponding vessel. Unequal partitions at the expense of the pulmonary artery are much more common than those of the aorta, which are generally rare.

Lateral positions take place with a truncoconal septum which may be straight, rotated, 

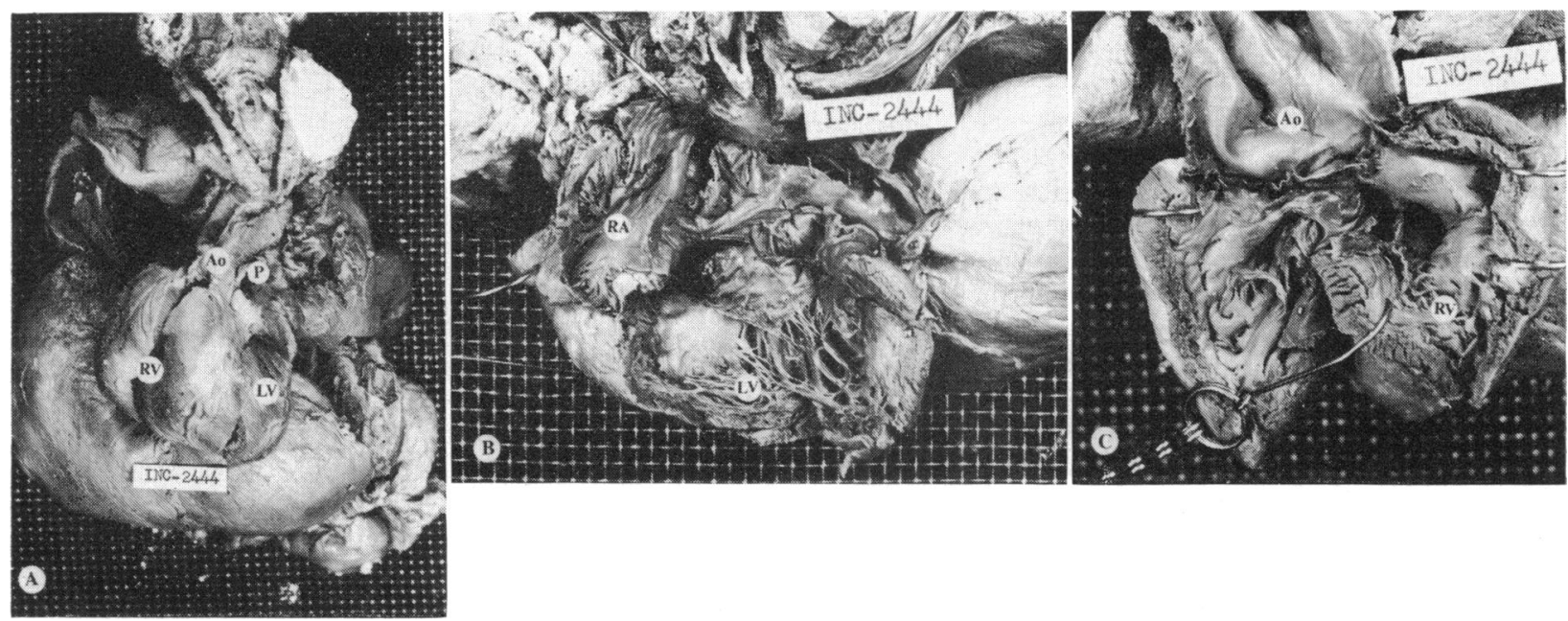

FIG. 9 Laevoversion with ventricular inversion and with transposition of the great vessels. (A) External view of the heart with the apex directed to the left. The greater lobe of the liver is to the left though the projection of this illustration seems to be placed to the right. The aorta $(A o)$ is anterior, parallel, and placed on the right of the pulmonary artery $(P) .(B)$ Internal view of the cardiac cavities placed on the left side. Atrioventricular relation. The anatomically right atrium $(R A)$ is placed on the left side and it connects with the anatomically left ventricle $(L V)$ placed on the left side. $(C)$ Relation of the great vessels to the ventricles. The aorta $(A o)$ arises in front of the crista supraventricularis from the anatomically right ventricle $(R V)$ placed on the right side.

FIG. IO Mirror-image dextrocardia with ventricular inversion and with transposition of the great vessels. $(A)$ External view of the heart. The apex is directed towards the right side. The greater lobe of the liver is also on the right side. The aorta $(A o)$ is anterior, parallel, and placed on the right side of the pulmonary artery $(P) .(B)$ Internal view of the cardiac chambers placed on the left side. Atrioventricular relation. The anatomically right atrium $(R A)$ is placed on the left side and it connects with the anatomically left ventricle $(L V)$ placed on the left. $(C)$ Relation of the great vessels with the ventricles. The aorta $(A o)$ arises in front of the crista supraventricularis from the anatomically right ventricle (RV) placed on the right side.
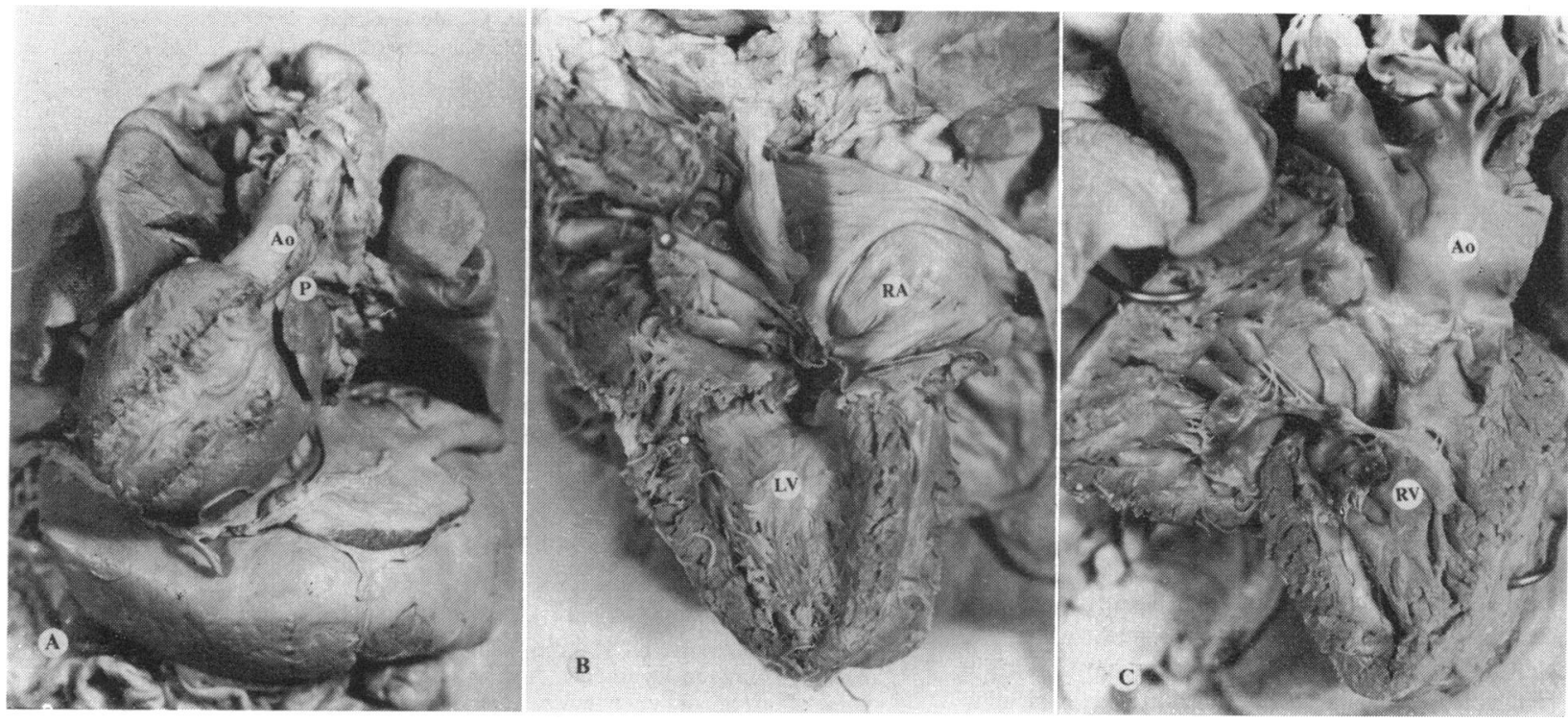
or absent. The normal disappearance of the conoventricular flange causes the truncusconus to become displaced, and its septum aligns with the primitive interventricular septum, thus causing one of the great vessels to arise from the anatomically right ventricle and the other from the anatomically left ventricle (Kramer, 1942). The early disappearance of the conoventricular flange causes the abnormal displacement of the truncus-conus towards the anatomically left ventricle, causing both vessels to originate from this ventricle or else one of them overrides the interventricular septum (de la Cruz and da Rocha, 1956), independently of the spatial position of the anatomically left ventricle.

This malformation is unusual and it is called laevoposition. The late disappearance of the conoventricular flange avoids the normal displacement of the truncus-conus, causing both vessels to arise from the anatomically right ventricle or else one of them overrides the interventricular septum, regardless of the spatial position of the anatomically right ventricle. This malformation is called dextroposition and it is the most common, because during certain stages of development the truncus-conus arises from the anatomically right ventricle.

The unequal partitions and lateral positions may appear isolated or combined with one another (de la Cruz and da Rocha, 1956).

\section{Malformations associated with mal- positions of the heart}

Associated malformations vary in frequency according to the malpositions of the heart. Mirror-image dextrocardia rarely shows associated cardiac malformations. According to Grant (1958) this takes place in 5 per 1000, and in this case the most common types (Campbell and Deuchar, 1966; Cooley and Billig, 1963) are atrial septal defect, ventricular septal defect, pulmonary valvular stenosis, aortic valvular stenosis, and persistent ductus arteriosus. Truncoconal malformations of the type of tetrad of Fallot or transposition of the great vessels are seen less frequently (Calderón Montero et al., 1965). On the contrary, in mirror-image dextrocardia with ventricular inversion, complex defects are common (Espino-Vela et al., 1959).

Dextroversions and laevoversions with or without ventricular inversion are frequently associated with complex defects (Hanson and Tabakin, 1961 ; Padmavati and Gupta, 1962; Campbell and Deuchar, 1965) such as single atrium, common atrioventricular canal, single ventricle, atresia of the atrioventricular orifices, and abnormalities of the venous pulmonary and systemic draining system. Atresias and stenosis of the pulmonary artery and transposition of the great vessels are the most common defects (Berri, I958; Campbell and Deuchar, 1965).

\section{References}

Berri, G. G. (1958). Dextrocardias y Levocardias. Talleres Gráficos Didot, S. R. L. Buenos Aires.

Calderón Montero, J., Márquez Blasco, J., Cerezo González, L., Sánchez Fernández-Villarán, E., Aza Fernandez-Nespral, V., and Torrecilla Martinez, I. (I965). Dextrocardias con aurículas 'in situ solito'. Revista Española de Cardiologia, 18, 40.

Campbell, M., and Deuchar, D. C. (1965). Dextrocardia and isolated laevocardia. I: Isolated laevocardia. British Heart fournal, 27, 69.

Campbell, M., and Deuchar, D. C. (1966). Dextrocardia and isolated laevocardia. II: Situs inversus and isolated dextrocardia. British Heart fournal, 28, 472 .

Cooley, D. A., and Billig, D. M. (1963). Surgical repair of congenital cardiac lesions in mirror image dextrocardia with situs inversus totalis. American fournal of Cardiology, 11, 518.

Davis, C. L. (1927). Development of the human heart from its first appearance to the stage found in embryos of twenty paired somites. Carnegie Institution of Washington Contributions to Embryology, 19, 245.

de la Cruz, M. V., and da Rocha, J. P. (1956). An ontogenetic theory for the explanation of congenital malformations involving the truncus and conus. American Heart fournal, 51, 782.

de la Cruz, M. V., Espino-Vela, J., Attie, F., and Muñoz Castellanos, L. (1967). An embryologic theory for ventricular inversions and their classification. American Heart fournal, 73, 777.

Espino-Vela, J., de la Cruz, M. V., Muñoz-Castellanos, L., Plaza, L., and Attie, F. (1970). Ventricular inversion without transposition of the great vessels in situs inversus. British Heart fournal, 32, 292.

Espino-Vela, J., Portillo, B., Anselmi, G., de la Cruz, M. V., and Reinhold, M. (1959). On a variety of the 'corrected' type of transposition of the great vessels associated with dextrocardia. A study of two cases with autopsy report. American Heart Fournal, 58, 250.

Grant, R. P. (1958). The syndrome of dextroversion of the heart. Circulation, 18, 25.

Hanson, J. S., and Tabakin, B. S. (196I). Primary and secondary dextrocardia. Their differentiation and the role of cineangiocardiography in diagnosing associated congenital cardiac defects. American fournal of Cardiology, 8, 275.

Jue, K. L., Adams, P., Jr., Pryor, R., Blount, S. G., Jr., and Edwards, J. E. (1966). Complete transposition of the great vessels in total situs inversus: anatomic, electrocardiographic and radiologic observations. American fournal of Cardiology, 17, 389.

Kramer, T. C. (1942). The partitioning of the truncus and conus and the formation of the membranous portion of the interventricular septum in the human heart. American fournal of Anatomy, 71, 343.

Lev, M., and Rowlatt, U. F. (I96I). The pathologic anatomy of mixed levocardia. A review of thirteen cases of atrial or ventricular inversion with or 
without corrected transposition. American fournal of Cardiology, 8, 216.

Licata, R. F. (1954). The human embryonic heart in the ninth week. American fournal of Anatomy, 94, 73.

Padmavati, S., and Gupta, S. (1962). Partial situs inversus with levocardia. An unusual combination of anomalies. Circulation, 26, 108.

Stanger, P., Benassi, R. C., Korns, M. E., Jue, K. L., and Edwards, J. E. (1968). Diagrammatic portrayal of variations in cardiac structure. Reference to transposition, dextrocardia, and the concept of four normal hearts. Circulation, 37, Suppl. IV.

Streeter, G. L. (1948). Developmental horizons in human embryos; description of age groups $\mathrm{XV}$, $\mathrm{XVI}, \mathrm{XVII}$, and XVIII, being the third issue of a survey of the Carnegie Collection. Contributions to Embryology, 32, 133.

Van Praagh, R., Van Praagh, S., Vlad, P., and Keith, J. D. (I964). Anatomic types of congenital dextrocardia. Diagnostic and embryologic implications. American fournal of Cardiology, 13, 5 Io. 